[Article]

www.whxb.pku.edu.cn

\title{
$\mathrm{HBF}_{4}$ 溶液中全铅液流电池
}

\author{
刘东阳 ${ }^{1,2}$ 程 杰 ${ }^{2, *}$ 潘军青 ${ }^{1} \quad$ 文越华 $^{2} \quad$ 曹高萍 $^{2}$ 杨裕生 ${ }^{1,2}$ \\ ('北京化工大学理学院, 北京 100029; ${ }^{2}$ 防化研究院, 北京 100191)
}

\begin{abstract}
摘要: 报道了一种 $\mathrm{HBF}_{4}$ 水溶液中的全铅液流电池, 正、负电极电解液均采用 $\mathrm{Pb}\left(\mathrm{BF}_{4}\right)_{2}$ 的 $\mathrm{HBF}_{4}$ 水溶液. 在酸性 的四氟硼酸铅电解液中考察了石墨电极和玻碳电极作为工作电极的循环伏安性能, 石墨电极较适于用作全铅 液流电池的正、负电极. 采用石墨电极作为电池的正、负电极并在四氟硼酸铅酸性电解液中进行充放电实验, 其 中 $\mathrm{Pb}\left(\mathrm{BF}_{4}\right)_{2}$ 浓度分别为 $0.5 、 1.0$ 和 $1.5 \mathrm{~mol} \cdot \mathrm{L}^{-1}$, 且保持游离的 $\mathrm{HBF}_{4}$ 浓度为 $1.0 \mathrm{~mol} \cdot \mathrm{L}^{-1}$. 该电池为单液流电池, 不需要隔膜分隔正、负极的电解液, 电流密度为 10.20 和 $40 \mathrm{~mA} \cdot \mathrm{cm}^{-2}$, 当限定充电容量为 $7.0 \mathrm{mAh} \cdot \mathrm{cm}^{-2}$, 放电电 压截止到 $1.0 \mathrm{~V}$ 时, 平均库仑效率大于 $87 \%$, 平均能量效率大于 $68 \%$; 当电解液采用 1.0 或 $1.5 \mathrm{~mol} \cdot \mathrm{L}^{-1} \mathrm{~Pb}\left(\mathrm{BF}_{4}\right)_{2}+$ $1.0 \mathrm{~mol} \cdot \mathrm{L}^{-1} \mathrm{HBF}_{4}$ 水溶液时, 在 10 及 $20 \mathrm{~mA} \cdot \mathrm{cm}^{-2}$ 电流下的能量效率最高可超过 $74 \%$.
\end{abstract}

关键词: 四氟硼酸; 石墨电极; 四氟嗍酸铅; 全铅液流电池

中图分类号: 0646.21

\section{All-Lead Redox Flow Battery in a Fluoroboric Acid Electrolyte}

\author{
LIU Dong-Yang ${ }^{1} \quad$ CHENG Jie ${ }^{2, *} \quad$ PAN Jun-Qing ${ }^{1} \quad$ WEN Yue-Hua ${ }^{2}$ \\ CAO Gao-Ping ${ }^{2} \quad$ YANG Yu-Sheng ${ }^{1,2}$ \\ ( ${ }^{1}$ College of Science, Beijing University of Chemical Technology, Beijing 100029, P. R. China; \\ ${ }^{2}$ Research Institute of Chemical Defence, Beijing 100191, P. R. China)
}

\begin{abstract}
An all-lead redox flow battery in a fluoroboric acid electrolyte is proposed. The same electrolyte was used as both the negative and positive electrodes, and it consists of a high concentration solution of $\mathrm{Pb}\left(\mathrm{BF}_{4}\right)_{2}$ in aqueous fluoroboric acid, i.e., $0.1,0.5,1.0$ and $1.5 \mathrm{~mol} \cdot \mathrm{L}^{-1} \mathrm{~Pb}\left(\mathrm{BF}_{4}\right)_{2}$ in $1.0 \mathrm{~mol} \cdot \mathrm{L}^{-1} \mathrm{HBF}_{4}$. The properties of the graphite and glassy carbon electrodes for both the positive and negative electrodes as current collectors were compared using cyclic voltammetry. We found that the graphite substrate was better than glassy carbon for both the negative electrode and the positive electrode. The all-lead redox flow battery was constructed using graphite substrates as both the positive and negative electrodes with a single electrolyte flow passing though the two electrodes. The performance of the batteries was evaluated using the constant current charge/discharge technique. Typically, an average coulombic efficiency of above $87 \%$ and an average energy efficiency of above $68 \%$ were obtained. An average energy efficiency of above $74 \%$ was achieved with electrolyte containing 1.0 or $1.5 \mathrm{~mol} \cdot \mathrm{L}^{-1} \mathrm{~Pb}\left(\mathrm{BF}_{4}\right)_{2}+1.0 \mathrm{~mol} \cdot \mathrm{L}^{-1} \mathrm{HBF}_{4}$ at current densities of 10 and $20 \mathrm{~mA} \cdot \mathrm{cm}^{-2}$.
\end{abstract}

Key Words: Fluoroboric acid; Graphite electrode; Lead fluoroboric acid; All lead redox flow battery

Received: June 8, 2011; Revised: August 15, 2011; Published on Web: August 29, 2011.

"Corresponding author. Email: chengjie_chj@sohu.com; Tel: +86-10-66705840.

The project was supported by the National Key Basic Research Program of China (973) (2010CB227204) and National Natural Science Foundation of China (50804050).

国家重点基础研究发展计划项目(973) (2010CB227204)和国家自然科学基金(50804050)资助

(C) Editorial office of Acta Physico-Chimica Sinica 


\section{1 引 言}

大规模储能在太阳能蓄电、风能蓄电、用电大 户蓄电和军用蓄电等领域的应用具有重要的现实 意义. ${ }^{1}$ 化学储能在扬水蓄能发电、压缩空气储能、超 级电容器储能这些能量储存系统中被列为理想的 一种. ${ }^{2,3}$ 由于液流电池储能的独特优势 ${ }^{4}$ 近年来发展 迅速, 液流电池的研究最早可追溯到 1884 年提出的 锌/氯电池, 但直到 Thaller ${ }^{5}$ 提出 $\mathrm{Cr} / \mathrm{Fe}$ 液流电池的概 念之后才有较多的关注和较快的进展, 包括发展比 较成熟的全钒液流电池在内, 离子交换膜的使用寿 命及电解液交叉污染问题一直是研究的重点问 题. ${ }^{6-10}$ 因此, 消除离子交换膜, 提高能量效率已经成 为流体电池研究的重点. 英国 Pletcher 课题组 ${ }^{11-18}$ 于 2004 年提出了一种新型铅酸单液流电池, 在电池中 只有一种反应物, 以酸性的甲基磺酸铅为电解液, 不需要离子交换膜, 但其能量效率大约 $65 \%$, 库仑 效率大于 $85 \%$, 仍需要改进.

为进一步提高铅酸单液流电池的性能, 本文将 电解液改为四氟硼酸铅酸性溶液, 探索了此情况下 全铅酸单液流电池的性能. 与甲基磺酸相比, 四氟 嗍酸分子量相对较低, 凝固点也比甲基磺酸的低, 因此电解液的低温性能好, 四氟硼酸的价格也是甲 基磺酸的一半. 而从电镀工业看, 氟硼酸铅镀层结 晶紧密细致、电流效率高. ${ }^{19}$ 因此, 我们推测四氟㸴 酸铅酸性溶液中全铅酸单液流电池的性能可能比 甲基磺酸中的性能高、成本低, 有利于产业化.

\section{2 实 验}

四氟嗍酸 $40 \%(w)$ 水溶液(汕头市西陇化工厂有 限公司)、黄色氧化铅(国药集团化学试剂有限公司) 均为分析纯. 所用溶剂为去离子水. 将计算量的黄 色氧化铅用少量蒸馏水调成糊状, 在不断摚拌的情 况下, 缓慢加入到 $40 \%(w)$ 氟硼酸水溶液中生成氟 嗍酸铅溶液, 配成铅浓度为 $0.1 、 0.5 、 1.0$ 和 $1.5 \mathrm{~mol} \cdot$ $\mathrm{L}^{-1}$ 的电解液, 其中游离氟嗍酸浓度保持 $1.0 \mathrm{~mol} \cdot \mathrm{L}^{-1}$.

采用三电极体系, 以循环伏安法分别测试石墨 电极及玻态碳电极作为正极或负极时的性能. 石墨 电极采用表观面积为 $0.1419 \mathrm{~cm}^{2}$ 的圆棒, 玻态碳电 极采用表观面积为 $0.1075 \mathrm{~cm}^{2}$ 的圆棒(两种电极都 用环氧树脂封住, 只露出一端表面, 使用前打磨并 用丙酮擦干表面), 辅助电极为纯铅电极 (电极面积 约为 $1.5 \mathrm{~cm} \times 3.0 \mathrm{~cm}$ ), 参比电极为 $\mathrm{Ag} / \mathrm{AgCl}$ (盐桥为 饱和硝酸钾). 正、负电极循环伏安测试电解液均为
$0.1 \mathrm{~mol} \cdot \mathrm{L}^{-1} \mathrm{~Pb}\left(\mathrm{BF}_{4}\right)_{2}+1.0 \mathrm{~mol} \cdot \mathrm{L}^{-1} \mathrm{HBF}_{4}$ 溶液, 正极测 试范围 0.70-1.75 V (vs Ag/ $\mathrm{AgCl}$,下同), 负极测试范 围 $-0.65-0.10 \mathrm{~V}$, 扫描速率分别为 $1 、 5 、 10 、 25$ 和 50 $\mathrm{mV} \cdot \mathrm{s}^{-1}$. 测试仪器为英国 Solartron $1280 \mathrm{Z}$ 型电化学 工作站.

充放电实验采用两电极体系模拟电池, 正、负 电极采用平板状石墨电极, 电极面积 $1.5 \mathrm{~cm} \times 3.0$ $\mathrm{cm}$, 电极间距约 $5 \mathrm{~mm}$, 实验采用烧杯式模拟电池 (溶液用磁力摚拌). 电解液采用上述 $0.5 、 1.0$ 和 1.5 $\mathrm{mol} \cdot \mathrm{L}^{-1}$ 氟硼酸铅的四氟嗍酸水溶液. 测试仪器为武 汉金诺电子科技有限公司生产的 LAND CT2001A 型电池测试系统. 充放电的电流密度分别为 $10 、 20$ 和 $40 \mathrm{~mA} \cdot \mathrm{cm}^{-2}$, 限定充电容量 $7.0 \mathrm{mAh} \cdot \mathrm{cm}^{-2}$, 放电 截止到 $1.0 \mathrm{~V}$.

\section{3 结果与讨论}

\section{1 集流体的循环伏安研究}

电极是负极活性物质铅及正极活性物质二氧 化铅沉积/溶解的载体, 影响反应动力学和结合力. ${ }^{20}$ 需要考虑石墨和玻态碳电极上铅及二氧化铅沉积 特性. 本文首先采用三电极体系研究了四氟嗍酸铅 酸性电解液中石墨和玻碳电极上铅及二氧化铅沉 积/溶解的性能.

\subsection{1 石墨和玻态碳电极正极循环伏安性能}

图 1(a) 为 $0.1 \mathrm{~mol} \cdot \mathrm{L}^{-1} \mathrm{~Pb}\left(\mathrm{BF}_{4}\right)_{2}+1.0 \mathrm{~mol} \cdot \mathrm{L}^{-1}$ $\mathrm{HBF}_{4}$ 电解液中石墨电极上的循环伏安图, 测试范围 0.70-1.75 V. 由图 1(a)可见, $5 \mathrm{mV} \cdot \mathrm{s}^{-1}$ 扫描速率下石 墨电极循环伏安曲线在 1.63 和 $1.12 \mathrm{~V}$ 处出现了明显 的氧化峰和还原峰, 对应二氧化铅的沉积和溶解. 电势高于 $1.55 \mathrm{~V}$ 时, 电极上的反应速度逐渐加快, 石 墨电极表面附近的薄层电解液中的 $\mathrm{Pb}^{2+}$ 失电子生成 二氧化铅附在电极表面. 随着电势的增大, 二氧化 铅的沉积量逐渐积累, 当电势增加到 $1.63 \mathrm{~V}$ 时, 氧化 电流得到最大值. 电势高于 $1.63 \mathrm{~V}$ 时, 因 $\mathrm{Pb}^{2+}$ 扩散过 程的限制及 $\mathrm{PbO}_{2}$ 与电极表面结合力和导电性等因 素影响, 氧化电流逐渐降低, 形成氧化峰. 当电势增 大到 $1.70 \mathrm{~V}$ 时, 发生析氧副反应. 回扫时, 当电势减 小到 $1.40 \mathrm{~V}$ 时, 石墨电极上开始进行还原反应, 沉积 的二氧化铅开始溶解, 电解液中的 $\mathrm{H}^{+}$扩散向 $\mathrm{PbO}_{2}$ 固 相、生成的 $\mathrm{Pb}^{2+}$ 扩散到电极表面附近的薄层电解液 中. 当电势降低到 $1.12 \mathrm{~V}$ 时, 还原反应速度最快, 还 原电流达到最大值. 当电势低于 $1.12 \mathrm{~V}$ 时, 因扩散传 质和二氧化铅耗尽而露出石墨电极表面等因素影 

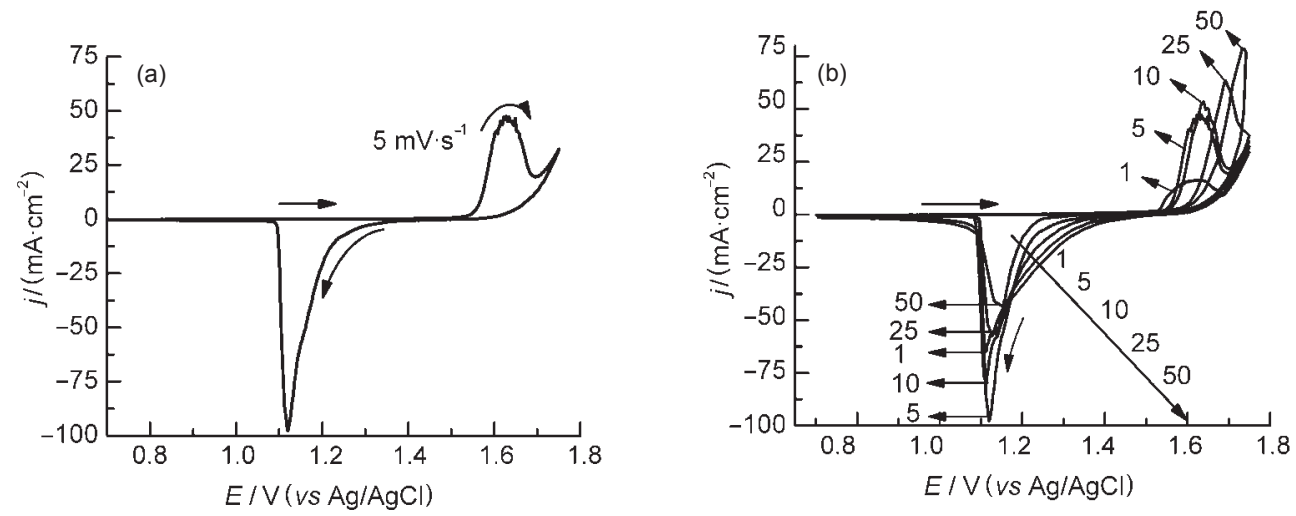

图 1 石墨正极在 $0.1 \mathrm{~mol} \cdot \mathrm{L}^{-1} \mathrm{~Pb}\left(\mathrm{BF}_{4}\right)_{2}+1.0 \mathrm{~mol}^{-1} \mathrm{HBF}_{4}$ 电解液中的循环伏安曲线

Fig.1 A cyclic voltammogram recorded on a graphite as positive electrode in

$0.1 \mathrm{~mol} \cdot \mathrm{L}^{-1} \mathrm{~Pb}\left(\mathrm{BF}_{4}\right)_{2}+1.0 \mathrm{~mol} \cdot \mathrm{L}^{-1} \mathrm{HBF}_{4}$ electrolyte

scan rate $/\left(\mathrm{mV} \cdot \mathrm{s}^{-1}\right)$ : (a) 5 ; (b) $1,5,10,25,50$

响, 还原电流迅速降低, 形成还原峰. 由电位越过还 原峰后电流急剧降低的现象推测, 形成峰的主要原 因是二氧化铅耗尽. 图 1(b)是石墨电极在不同扫描 速率时的循环伏安曲线, 测试范围 0.70-1.75 V, 扫 描速率为 $1 、 5 、 10 、 25$ 和 $50 \mathrm{mV} \cdot \mathrm{s}^{-1}$. 由图 1(b)可见, 随 着扫描速率增大, 氧化峰电势正移、氧化峰电流增 大, 而扫描速率为 $5 \mathrm{mV} \cdot \mathrm{s}^{-1}$ 时, 还原峰电流最大. 还 原峰电流的大小与氧化反应时二氧化铅在石墨电 极表面的沉积量有关, 可以推断扫描速率高于 5 $\mathrm{mV} \cdot \mathrm{s}^{-1}$ 时二氧化铅的沉积量较小, 因而还原峰电流 低.

图 2 是玻态碳电极在 $0.1 \mathrm{~mol} \cdot \mathrm{L}^{-1} \mathrm{~Pb}\left(\mathrm{BF}_{4}\right)_{2}+1.0$ $\mathrm{mol} \cdot \mathrm{L}^{-1} \mathrm{HBF}_{4}$ 电解液中不同扫描速率时的循环伏安 曲线, 测试范围 0.70-1.75 V, 摚拌速度与石墨电极 测试条件相同. 当电势高于 $1.56 \mathrm{~V}$ 时, 氧化反应沉积

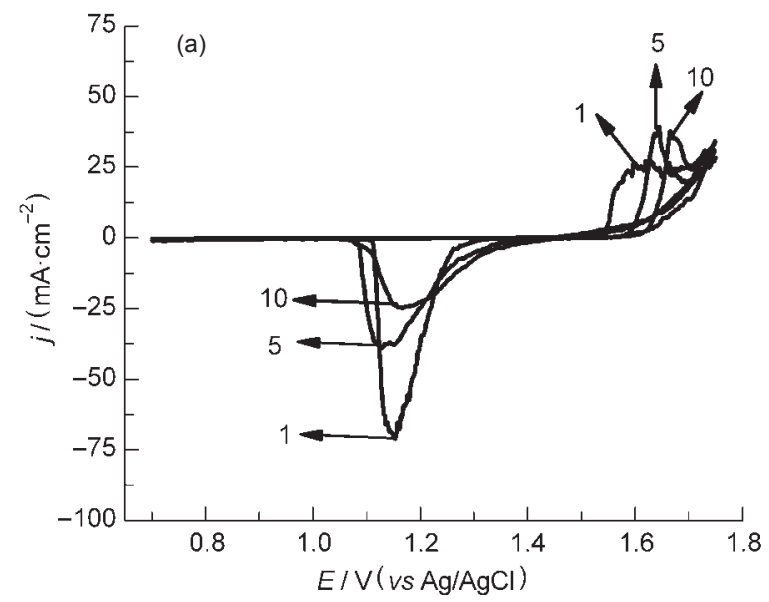

二氧化铅, 扫描速率为 $1 、 5$ 和 $10 \mathrm{mV} \cdot \mathrm{s}^{-1}$ 的曲线当氧 化电流达到最大而后开始降低, 其后随析氧反应发 生, 电流又有回升. 而扫描速率为 25 和 $50 \mathrm{mV} \cdot \mathrm{s}^{-1}$ 时, 回扫后曲线有交叉, 说明高扫描速率时 $\mathrm{PbO}_{2}$ 沉 积和析氧反应区域重叠. 与图 1 比较, 虽玻态碳电极 和石墨电极上 $\mathrm{PbO}_{2}$ 沉积的氧化峰电位差别不大, 但 玻态碳电极上氧化峰电流与还原峰电流比同扫描 速率的石墨电极上均小, 而且玻态碳电极上有明显 还原电流的电位比同扫描速率的石墨电极上低. 可 能是由于石墨表面比玻态碳表面更容易生成亲水 性官能团, 从而可能降低沉积/溶解界面阻力、增强 沉积层与表面的结合力. 可见石墨电极更利于二氧 化铅的沉积和溶解, 因此选石墨电极作为全铅液流 电池的正极.

\subsection{2 石墨和玻态碳电极负极循环伏安性能}

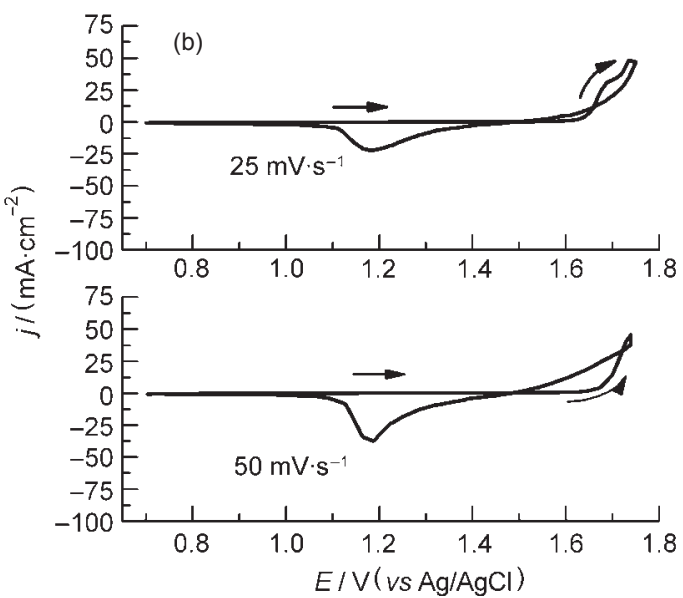

图 2 玻态碳正极在 $0.1 \mathrm{~mol} \cdot \mathrm{L}^{-1} \mathrm{~Pb}\left(\mathrm{BF}_{4}\right)_{2}+1.0 \mathrm{~mol} \cdot \mathrm{L}^{-1} \mathrm{HBF}_{4}$ 电解液中的不同扫描速率的循环伏安曲线

Fig.2 Cyclic voltammograms recorded on a glassy carbon as positive electrode in $0.1 \mathrm{~mol} \cdot \mathrm{L}^{-1} \mathrm{~Pb}\left(\mathrm{BF}_{4}\right)_{2}+1.0 \mathrm{~mol} \cdot \mathrm{L}^{-1} \mathrm{HBF}_{4}$ electrolyte scan rate $/\left(\mathrm{mV} \cdot \mathrm{s}^{-1}\right)$ : (a) $1,5,10$; (b) 25,50 

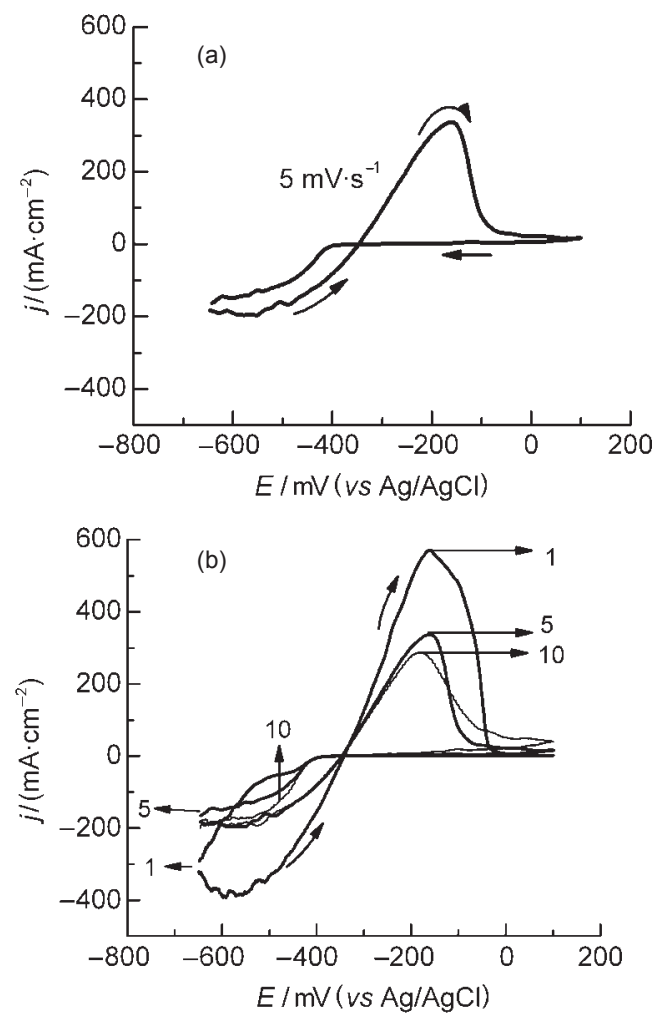

图 3 石墨负极在 $0.1 \mathrm{~mol} \cdot \mathrm{L}^{-1} \mathrm{~Pb}\left(\mathrm{BF}_{4}\right)_{2}+1.0 \mathrm{~mol} \cdot \mathrm{L}^{-1} \mathrm{HBF}_{4}$ 电解液中的循环伏安曲线

Fig.3 A cyclic voltammogram recorded on a graphite as anode electrode in $0.1 \mathrm{~mol} \cdot \mathrm{L}^{-1} \mathrm{~Pb}\left(\mathrm{BF}_{4}\right)_{2}+1.0 \mathrm{~mol} \cdot \mathrm{L}^{-1}$ $\mathrm{HBF}_{4}$ electrolyte

scan rate $/\left(\mathrm{mV} \cdot \mathrm{s}^{-1}\right)$ : (a) 5 ; (b) $1,5,10$

图 3 为石墨负极在 $0.1 \mathrm{~mol} \cdot \mathrm{L}^{-1} \mathrm{~Pb}\left(\mathrm{BF}_{4}\right)_{2}+1.0$ $\mathrm{mol} \cdot \mathrm{L}^{-1} \mathrm{HBF}_{4}$ 电解液中循环伏安曲线, 测试范 围- $0.65-0.10 \mathrm{~V}$. 可见电极自 $-0.40 \mathrm{~V}$ 负向极化时 发生铅电沉积反应而沉积电流随极化增加不断增 加, 石墨电极表面覆盖的沉积铅不断累积. 电位达 到 $-0.50 \mathrm{~V}$ 以下时沉积电流出现极限电流似平台, 1 $\mathrm{mV} \cdot \mathrm{s}^{-1}$ 的扫描速率实验可观察到析氢. $1 、 5$ 和 10 $\mathrm{mV} \cdot \mathrm{s}^{-1}$ 的沉积过程在 $-0.50 \mathrm{~V}$ 左右均出现极限电流 似平台且扫描速率高时极限电流密度高, 是比较典 型的沉积/溶解反应特征. $1 \mathrm{mV} \cdot \mathrm{s}^{-1}$ 的曲线在 $-0.55 \mathrm{~V}$ 以下时电流增大并在回扫时出现电流峰值, 可能是 低扫描速率时析氢扰动、 $\mathrm{Pb}^{2+}$ 扩散控制电极过程及 沉积层比表面增大等因素造成的. 5 和 $10 \mathrm{mV} \cdot \mathrm{s}^{-1}$ 的 曲线在回扫时没有出现沉积电流峰值, 应该和电极 过程由 $\mathrm{Pb}^{2+}$ 扩散控制有关. 极化电位自负向返折后, 铅沉积电流较电位返折前增加, 也与 $\mathrm{Pb}^{2+}$ 扩散控制 有关. 电极电位在 $-0.35 \mathrm{~V}$ 左右达到电流零点, 而后 正向极化时开始铅的溶解过程, 随着极化增加电流 不断增加并在 $-0.16 \mathrm{~V}$ 左右达到电流峰值, 其后较

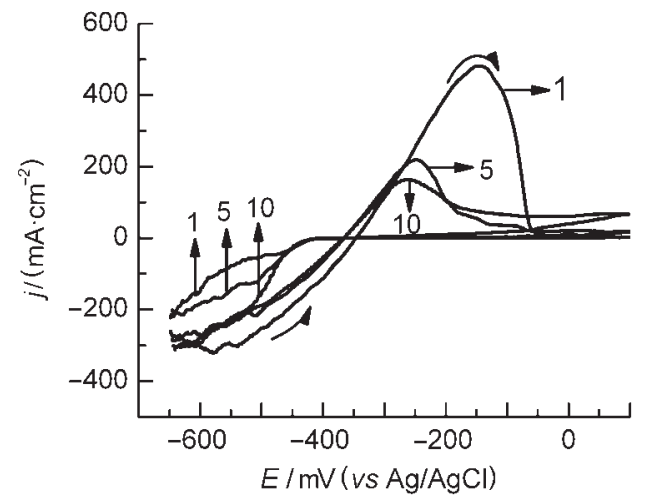

图 4 玻态碳负极不同扫描速率时的循环伏安曲线

Fig.4 Cyclic voltammograms recorded on a glassy carbon as anode electrode at different scan rates electrolyte: $0.1 \mathrm{~mol} \cdot \mathrm{L}^{-1} \mathrm{~Pb}\left(\mathrm{BF}_{4}\right)_{2}+1.0 \mathrm{~mol} \cdot \mathrm{L}^{-1} \mathrm{HBF}_{4}$, scan rate $/\left(\mathrm{mV} \cdot \mathrm{s}^{-1}\right): 1,5,10$

快降低. 这说明在 $-0.16 \mathrm{~V}$ 以上时石墨电极表面的 铅覆盖膜很快耗尽. 相对其他扫描速率, $1 \mathrm{mV} \cdot \mathrm{s}^{-1}$ 时 溶解峰电流相对较高, 达到 $0.57 \mathrm{~A} \cdot \mathrm{cm}^{-2}$. 随着扫描 速率增大, 沉积极限电流增加但溶解峰电流降低, 说明溶解峰电流主要受控于表面铅的沉积量.

图 4 是玻态碳负极在 $0.1 \mathrm{~mol} \cdot \mathrm{L}^{-1} \mathrm{~Pb}\left(\mathrm{BF}_{4}\right)_{2}+1.0$ $\mathrm{mol} \cdot \mathrm{L}^{-1} \mathrm{HBF}_{4}$ 电解液中不同扫描速率的循环伏安曲 线, 测试范围 $-0.65-0.10 \mathrm{~V}$, 搅拌速度与石墨电极 测试条件相同. 由图 4 可见, 玻态碳电极上铅的沉 积/溶解情况和石墨电极上类似, 但 $1 、 5$ 和 $10 \mathrm{mV} \cdot \mathrm{s}^{-1}$ 的沉积过程的极限电流似平台不明显, 可能析氢及 其对电极表面的扰动较石墨电极严重. 玻态碳电极 上的溶解峰电流在 $1 \mathrm{mV} \cdot \mathrm{s}^{-1}$ 扫描速率时较其它扫描 速率峰值相对较高, 达到 $0.48 \mathrm{~A} \cdot \mathrm{cm}^{-2}$, 但各扫描速 率下玻态碳电极比石墨电极上溶解峰电流相对较 低. 说明在同样情况下, 玻态碳电极上沉积铅的量 及沉积效率低于石墨电极上. 综合考虑石墨电极更 适合作为氟硼酸铅酸性电解液中铅的沉积/溶解反 应的集流体.

\section{2 $\mathrm{HBF}_{4}$ 全铅液流电池体系恒流充放电性能}

我们对 $\mathrm{C}-\mathrm{C}$ 电池体系进行了恒流充放电性能测 试, 分别以 $10 、 20$ 和 $40 \mathrm{~mA} \cdot \mathrm{cm}^{-2}$ 电流密度充放电并 限制充电容量为 $31.5 \mathrm{mAh} \cdot \mathrm{cm}^{-2}$, 放电截止到 $1.0 \mathrm{~V}$. 对电池体系性能进行了恒流充放电电压、库仑效 率、能量效率和电压效率的分析.

以石墨电极为正、负极集流体, 采用烧杯式模 拟电池测试了单液流全铅电池体系在 $1.5 \mathrm{~mol} \cdot \mathrm{L}^{-1}$ $\mathrm{Pb}\left(\mathrm{BF}_{4}\right)_{2}+1.0 \mathrm{~mol} \cdot \mathrm{L}^{-1} \mathrm{HBF}_{4}$ 溶液中的充放电性能, 其 中电极没有经过活化, 电极面积 $1.5 \mathrm{~cm} \times 3.0 \mathrm{~cm}$, 在 

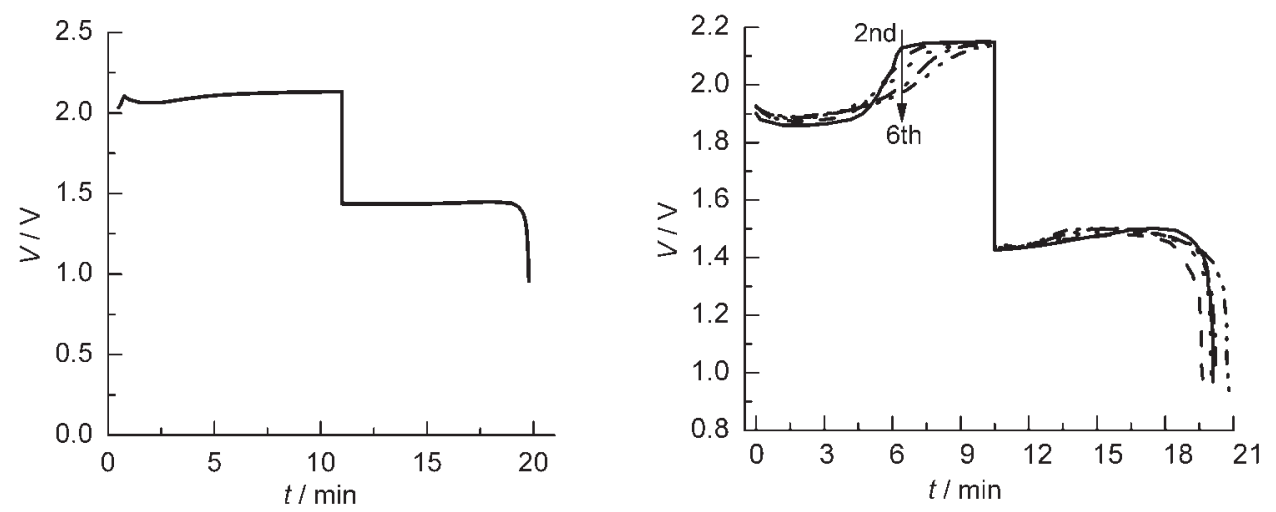

图 5 单液流全铅电池初始恒流充放电的电压一时间曲线

Fig.5 All lead single flow battery initial charge/discharge voltage-time graph

electrolyte: $1.5 \mathrm{~mol} \cdot \mathrm{L}^{-1} \mathrm{~Pb}\left(\mathrm{BF}_{4}\right)_{2}+1.0 \mathrm{~mol} \cdot \mathrm{L}^{-1} \mathrm{HBF}_{4}$; (a) 1st charge/discharge; (b) 2nd-6th charge/discharge

表 1 全铅电池体系 3 种电解液浓度下各电流密度的效率

Table 1 Efficiency of all lead redox flow battery system recorded at three types of electrolyte concentrations under different current densities

\begin{tabular}{ccccc}
\hline Electrolyte & $j /\left(\mathrm{mA} \cdot \mathrm{cm}^{-2}\right)$ & Average coulombic efficiency/\% & Average energy efficiency/\% & Average potential efficiency/\% \\
\hline $0.5 \mathrm{~mol} \cdot \mathrm{L}^{-1} \mathrm{~Pb}\left(\mathrm{BF}_{4}\right)_{2}+1.0 \mathrm{~mol} \cdot \mathrm{L}^{-1} \mathrm{HBF}_{4}$ & 10 & 87.39 & 72.58 & 83.05 \\
& 20 & 91.09 & 72.32 & 79.39 \\
& 40 & 93.81 & 68.44 & 72.96 \\
$1.0 \mathrm{~mol} \cdot \mathrm{L}^{-1} \mathrm{~Pb}\left(\mathrm{BF}_{4}\right)_{2}+1.0 \mathrm{~mol} \cdot \mathrm{L}^{-1} \mathrm{HBF}_{4}$ & 10 & 90.80 & 74.95 & 82.54 \\
& 20 & 93.68 & 74.42 & 79.44 \\
$1.5 \mathrm{~mol} \cdot \mathrm{L}^{-1} \mathrm{~Pb}\left(\mathrm{BF}_{4}\right)_{2}+1.0 \mathrm{~mol} \cdot \mathrm{L}^{-1} \mathrm{HBF}_{4}$ & 10 & 96.57 & 70.27 & 72.77 \\
& 20 & 91.36 & 74.62 & 81.68 \\
& 40 & 93.87 & 74.55 & 79.42 \\
\hline
\end{tabular}

$40 \mathrm{~mA} \cdot \mathrm{cm}^{-2}$ 的电流密度下充放电并限制充电容量 $7.0 \mathrm{mAh} \cdot \mathrm{cm}^{-2}$, 典型的充放电曲线见图 5. 可见, 首次 充电时, 电池电压超过 $2.0 \mathrm{~V}$, 初次放电时, 电流效率 仅 $83.6 \%$ (6 次的充放电电流效率分别为 $83.6 \%$ 、 $91.9 \% 、 87.0 \% 、 91.4 \% 、 92.9 \%$ 和 $97.5 \%)$, 与初次充电 正、负电极的析氧和析氢等有关. 由图 5(b) 可见, 经 初次充放电后, 第二次充电电池的初始电压就明显 下降, 应和正、负电极上均有少量活性物质不能完 全溶解有关. 第二次放电的电流效率达到 $91.9 \%$, 到 第六次放电, 电流效率达到 $97.5 \%$, 并基本稳定在 $97 \%$ 以. 可见, 数次充放电后单液流全铅电池即可 达到稳定性能, 平均放电电压可达 $1.5 \mathrm{~V}$, 电池的平 均库仑效率达到了 $97 \%$ 以上, 平均能量效率达到了 $72.88 \%$.

实验测试了不同铅浓度、不同电流密度下全铅 液流电池的性能, 结果总结在表 1 中. 可见, 电池充 放电的电压效率随电流密度的增大而降低, 而不同 电解液浓度的电池体系中充放电电流密度增大时 库仑效率高, 即电流密度为 $40 \mathrm{~mA} \cdot \mathrm{cm}^{-2}$ 时库仑效率 最高. 平均库仑效率随电解液浓度的增大而增大,
即电解液为 $1.5 \mathrm{~mol} \cdot \mathrm{L}^{-1} \mathrm{~Pb}\left(\mathrm{BF}_{4}\right)_{2}+1.0 \mathrm{~mol} \cdot \mathrm{L}^{-1} \mathrm{HBF}_{4}$ 时充放电平均库仑效率可达 $97 \%$ 以上. 各电解液浓 度、各电流密度充放电下能量效率达到 $68 \%$ 以上, 每种电解液浓度下的电池在电流密度为 $10 \mathrm{~mA}$. $\mathrm{cm}^{-2}$ 时能量效率最高, 可保持在 $72 \%$ 以上. 在之前英 国 Derek Pletcher 课题组研究的甲基磺酸铅电池体 系能量效率约为 $65 \%\left(\sim 20 \mathrm{~mA} \cdot \mathrm{cm}^{-2}\right),{ }^{11-18}$ 与之相比 我们的研究的体系性能有了较大提高.

\section{4 小 结}

综合以上的实验结果, 可以得到以下结论:

(1) 氟嗍酸铅酸性溶液中, 石墨电极作为全铅液 流电池的正极及负极集电极比玻态碳电极效果好.

(2) 氟嗍酸铅酸性溶液为电解液, 以石墨电极为 正负电极集流体实验了全铅液流电池, 数次充放电 循环内电池可以达到稳定性能, 不同电解液浓度、 不同电流密度下平均库仑效率达到 $87 \%-97 \%$; 平 均能量效率达到 $68 \%-74 \%$, 电解液浓度和电流密度 对库仑效率和能量效率都有影响. 


\section{References}

(1) Yang, Y. S.; Zhang, L.; Wen, Y. H.; Cheng, J.; Cao, G. P. Chin J. Power Sources 2007, 31, 175. [杨裕生, 张 立, 文越华, 程 杰, 曹高萍. 电源技术, 2007, 31, 175.]

(2) Dell, R. M. Solid State Ionics 2000, 134, 139.

(3) Pan, J. Q.; Sun, Y. Z.; Wang, Z. H.; Wan, P. Y.; Liu, X. G.; Fan, M. H. J. Mater. Chem. 2007, 17, 4820.

(4) Bae, C. H.; Roberts, E. P. L.; Dryfe, R. A. W. Electrochim. Acta 2002, 48, 279.

(5) Thaller, L. H. Electrically Rechargeable Redox Flow Cell. US Patent 3996064, 1974.

(6) Wang, W. H.; Wang, X. D. Electrochim. Acta 2007, 52, 6755.

(7) Wen, Y. H.; Zhang, H. M.; Qian, P.; Zhao, P.; Zhou, H. T.; Yi, B. L. Acta Phys.-Chim. Sin. 2006, 22, 403. [文越华, 张华民, 钱 鹏, 赵 平, 周汉涛, 衣宝廉. 物理化学学报, 2006, 22, 403.]

(8) Zhao, P.; Zhang, H. M.; Zhou, H. T.; Chen, J.; Gao, S. J.; Yi, B. L. J. Power Sources 2006, 162, 1416.

(9) Skyllas-Kazacos, M. J. Power Sources 2003, 124, 299.

(10) Oriji, G.; Katayama, Y.; Miura, T. Electrochim. Acta 2004, 49, 3091.

(11) Hazza, A.; Pletcher, D.; Wills, R. Phys. Chem. Chem. Phys.
2004, 6, 1773.

(12) Pletcher, D.; Wills, R. Phys. Chem. Chem. Phys. 2004, 6, 1779.

(13) Pletcher, D.; Wills, R. J. Power Sources 2005, 149, 96.

(14) Hazza, A.; Pletcher, D.; Wills, R. J. Power Sources 2005, 149, 103.

(15) Pletcher, D.; Zhou, H. T.; Kear, G.; John, L. C. T.; Walsh, F. C.; Wills, R. G. A. J. Power Sources 2008, 180, 621.

(16) Pletcher, D.; Zhou, H. T.; Kear, G.; John, L. C. T.; Walsh, F. C.; Wills, R. G. A. J. Power Sources 2008, 180, 630.

(17) Li, X. H.; Pletcher, D.; Walsh, F. C. Electrochim. Acta 2009, 54, 4688.

(18) Collins, J.; Kear, G.; Li, X. H.; Low, C. T. J.; Pletcher, D.; Tangirala, R.; Duncan,S.C.; Walsh, F. C.; Zhang, C. P. J. Power Sources 2010, 195, 1731 .

(19) Zeng, H. L.; Wu, Z. D.; Chen, J. W.; Lü, P. R.; Qin, Y. W. Handbook of Electroplate Technology, 2nd ed.; China Machine Press: Beijing, 1997; pp 243-245. [曾华梁, 吴仲达, 陈钧武, 吕佩仁, 秦月文. 电镀工艺手册. 第二版. 北京: 机械工业出版 社, 1997: 243-245.]

(20) Bernardi, D.; Pawlikowski, E.; Newman, J. J. Electrochem. Soc. 1985, 132,5 . 